\title{
Comparison of the clinical efficacy of medical treatment of symptomatic benign prostatic hyperplasia between normal and obese patients
}

\begin{abstract}
Seung Hwan Lee ${ }^{1}$, Cheol Young Oh${ }^{2}$, Kyung Kgi Park ${ }^{1}$, Mun Su Chung ${ }^{1}$, Se Jeong Yoo ${ }^{1}$ and Byung Ha Chung ${ }^{1}$
We aimed to investigate the difference in efficacy of medical treatment of symptomatic benign prostatic hyperplasia (BPH) between normal and obese patients with BPH; obesity was determined by either body mass index (BMI) or waist circumference (WC). In this 12-week prospective observational study, a total of 175 patients aged $\geqslant 40$ years with International Prostate Symptom Scores (IPSS) $\geqslant 12$ points and prostate volume $\geqslant 20 \mathrm{ml}$ were prospectively enrolled. The patients were divided into two groups according to BMI or WC. Patients received the doxazosin gastrointestinal therapeutic system (GITS) at a dose of $4 \mathrm{mg}$ once per day for 12 weeks. The changes from baseline in the IPSS, maximal urinary flow rate $\left(Q_{\max }\right)$, post-void residual volume, quality of life $(Q \circ L)$ scores and adverse events (AEs) were analysed. Of the 175 enrolled patients, 132 completed the study. Sixty-seven patients had BMI $>23 \mathrm{~kg} \mathrm{~m}^{-2}$, and 43 had WC $>90 \mathrm{~cm}$. Obese patients represented by WC $>90 \mathrm{~cm}$ or BMI $\geqslant 23 \mathrm{~kg} \mathrm{~m}^{-2}$ had a significantly greater prostate volume compared with non-obese patients at baseline. Total IPSS was significantly higher in the WC $>90 \mathrm{~cm}$ group compared to the WC $\leqslant 90 \mathrm{~cm}$ group. Total IPSS was positively correlated with prostate volume $(P=0.031)$ and WC $(P=0.045)$. All groups showed significant improvements in total IPSS and QoL at 12 weeks. However, the improvement of total IPSS was greater in the high-BMI and high-WC groups. The most frequent AE was dizziness $(n=13)$, and it was significantly lower in the obese BPH patients. Obesity was associated with increased prostate volume and lower urinary tract symptoms. Alpha-blockers appear to be efficacious for controlling symptoms, especially in obese men.
\end{abstract}

Asian Journal of Andrology (2011) 13, 728-731; doi:10.1038/aja.2011.5; published online 18 April 2011

Keywords: Alpha-blocker; benign prostatic hyperplasia; body mass index; prostate; waist circumference

\section{INTRODUCTION}

Lower urinary tract symptoms (LUTS) and obesity are common in older men and may greatly affect their quality of life. Furthermore, epidemiological data demonstrate increasing prevalence of not only LUTS secondary to benign prostatic hyperplasia (BPH) but also obesity as men age. ${ }^{1,2}$ The Korean National Health and Nutrition Surveys reported an increase in the prevalence of obesity in South Korea from 1995 to 2001 and an age-related increase in the prevalence of obesity in Korean adults in $2001 .^{3}$ The prevalence of clinical benign prostatic hyperplasia was reported to be $10.6 \%-31 \%$ in men over 50 years of age, with an age-related increase in South Korea. ${ }^{4,5}$ Positive associations between anthropometric measures of obesity and LUTS have been observed in several studies. ${ }^{6-8}$ This association indicates that modifiable risk factors may play a role in the pathogenesis of BPH.

We previously reported that the number of patients treated for $\mathrm{BPH}$ is rapidly increasing in Korea, and, non-invasive medical therapy is increasingly being chosen as the primary treatment option. ${ }^{9}$ Of the medications for BPH, the doxazosin gastrointestinal therapeutic system (GITS) has been effective and well tolerated as therapy for Korean $\mathrm{BPH}$ patients with or without concomitant hypertension. ${ }^{10}$ Although there are many studies concerning the clinical efficacy of doxazosin
GITS, there is a paucity of reports concerning the difference in efficacy between normal and obese patients. In the present study, we aimed to investigate the efficacy of doxazosin GITS in patients with BPH with respect to body mass index (BMI) and waist circumference (WC).

\section{MATERIALS AND METHODS}

Study design

This was a 12-week prospective observational study conducted in our institution, Yonsei University Health System from June 2009 to May 2010. Before initiating this study, approval was granted by the local institutional review board, and patients provided informed consent.

Eligible patients with BPH/LUTS attending a urology clinic for the first time were enrolled. At the initial visit, height, weight and WC were measured in all enrolled patients. The signs of BPH were assessed through the routine evaluation of $\mathrm{BPH}$ using transrectal ultrasound of the prostate, maximal urinary flow rate $\left(\mathrm{Q}_{\max }\right)$ assessed by uroflowmetry, post-void residual volume (PVR) assessed by ultrasound, International Prostate Symptom Score (IPSS), urine analysis and serum prostate-specific antigen (PSA) determination. The BMI of each patient was calculated as the body weight in kilograms divided by the square of the height in meters. After the initial evaluation,

${ }^{1}$ Department of Urology, Yonsei University Health System, Seoul, Korea and ${ }^{2}$ Department of Urology, Hallym University, Anyang 431-070, Chuncheon, Korea Correspondence: Professor BH Chung (chung646@yuhs.ac)

Received: 3 November 2010; Revised: 19 December 2010; Accepted: 11 January 2011; Published online: 18 April 2011 
patients were assigned to receive doxazosin GITS at a dose of $4 \mathrm{mg}$ once per day for 12 weeks. During 4 and 12 weeks after medication start all patients were evaluated via IPSS, uroflowmetry $\left(\mathrm{Q}_{\max }\right)$ and PVR. At each visit, adverse events (AEs) were recorded.

\section{Patients}

A total of 175 patients were prospectively enrolled in the study. All patients were divided into two groups, normal BMI $\left(n=89,23 \mathrm{~kg} \mathrm{~m}^{-2}\right.$ or less) and overweight or obese BMI ( $n=86,23 \mathrm{~kg} \mathrm{~m}^{-2}$ or above), according to the Asia-Pacific obesity criteria. ${ }^{11}$ We also categorized patients into two groups based on WC: normal waist $(\leqslant 90 \mathrm{~cm})$ and central obesity $(>90 \mathrm{~cm})$. The inclusion criteria were men 40 years of age and older with a total IPSS of 12 or higher and a prostate volume $\geqslant 20 \mathrm{ml}$ as determined by transrectal ultrasound without any relevant medical history or underlying comorbidities. Patients were excluded if they had neurogenic bladder dysfunction, confirmed prostate cancer, acute or chronic urinary retention status, acute or chronic prostatitis within the previous 3 months, PSA levels $>10 \mathrm{ng} \mathrm{ml}^{-1}$, a history of recurrent urinary tract infection or bladder stones, and previous transurethral resection of the prostate or other surgical interventions related to BPH. Of the 175 enrolled patients, 132 completed the study. Forty-three discontinued the trial, of whom 17 were lost to follow-up, 6 discontinued because the drug was not effective and 17 experienced AEs (e.g., dizziness or hypotension) (Figure 1).

\section{Statistical analysis}

The intent-to-treat population included all randomized patients who took one or more doses of the study drug.

All data are presented as mean \pm s.e.m. and we analysed the data using SPSS (version 12.0; Chicago, IL, USA). The changes from baseline in total IPSS, quality of life (QoL) scores, $\mathrm{Q}_{\max }$ and PVR were analysed using paired Student's $t$-tests. An independent $t$-test was used to compare data between the normal and high-BMI or -WC groups. After performing a covariate analysis of variance, adjusted for age and prostate volume, the significance of the differences in total IPSS, QoL scores, $Q_{\max }$ and PVR among groups based on baseline BMI and WC was examined using ANCOVA with subsequent linear contrasts. Post hoc analysis compared the mean changes from baseline to week 12 in total IPSS, IPSS QoL scores, $Q_{\max }$ and PVR using a two-sided $P$ value of $<0.05$ to determine significance. The chi-square test was used to determine the statistical significance of differences in AEs between the normal BMI ( $n=89,23 \mathrm{~kg} \mathrm{~m}^{-2}$ or less) and obese BMI $\left(n=86,23 \mathrm{~kg} \mathrm{~m}^{-2}\right.$ or above) groups or normal waist and central obesity groups. We used linear regression to examine the prognostic factors for the improvement of total IPSS. A $P$ value of $<0.05$ was considered significant.

\section{RESULTS}

Details about the patients enrolled are shown in Figure 1, and the baseline clinical characteristics according to BMI or WC are summarized in Table 1. The baseline data of the initially enrolled 175 patients are balanced with that of the 132 patients who finished the study. Of the 132 men who completed the study, 67 patients had a BMI above $23 \mathrm{~kg} \mathrm{~m}^{-2}$, and 43 patients had a WC above $90 \mathrm{~cm}$. The overall mean age was $59.8 \pm 4.1$ years, with a mean BMI of $21.7 \pm 3.5 \mathrm{~kg} \mathrm{~m}^{-2}$ and a mean WC of $79.9 \mathrm{~cm}$. The mean total IPSS was $20.7 \pm 2.1$, the mean QoL score was $4.2 \pm 0.5$ and the mean prostate volume was $32.3 \pm 5.1$ $\mathrm{ml}$. Obese patients represented by WC $>90 \mathrm{~cm}(P=0.026)$ or BMI $\geqslant 23 \mathrm{~kg} \mathrm{~m}^{-2}(P=0.039)$ had a significantly greater prostate volume compared with non-obese patients (Table 1). Total IPSS was significantly higher in the WC $>90 \mathrm{~cm}$ group compared to the $\mathrm{WC} \leqslant 90 \mathrm{~cm}$ group (22.4 versus 19.1, respectively). The serum PSA and $Q_{\max }$ values were significantly lower only in the WC $>90 \mathrm{~cm}$ group $(P<0.05)$. The residual volumes were significantly higher in the $\mathrm{WC}>90 \mathrm{~cm}$ group $(P<0.05)$. In the regression analyses, after adjusting for age, total IPSS was positively correlated with prostate volume $(P=0.031)$ and WC $(P=0.045)$ (Table 2).

Figure 2 shows the changes in the total IPSS and QoL scores for normal and obese patients after alpha-blocker medication (4 and 12

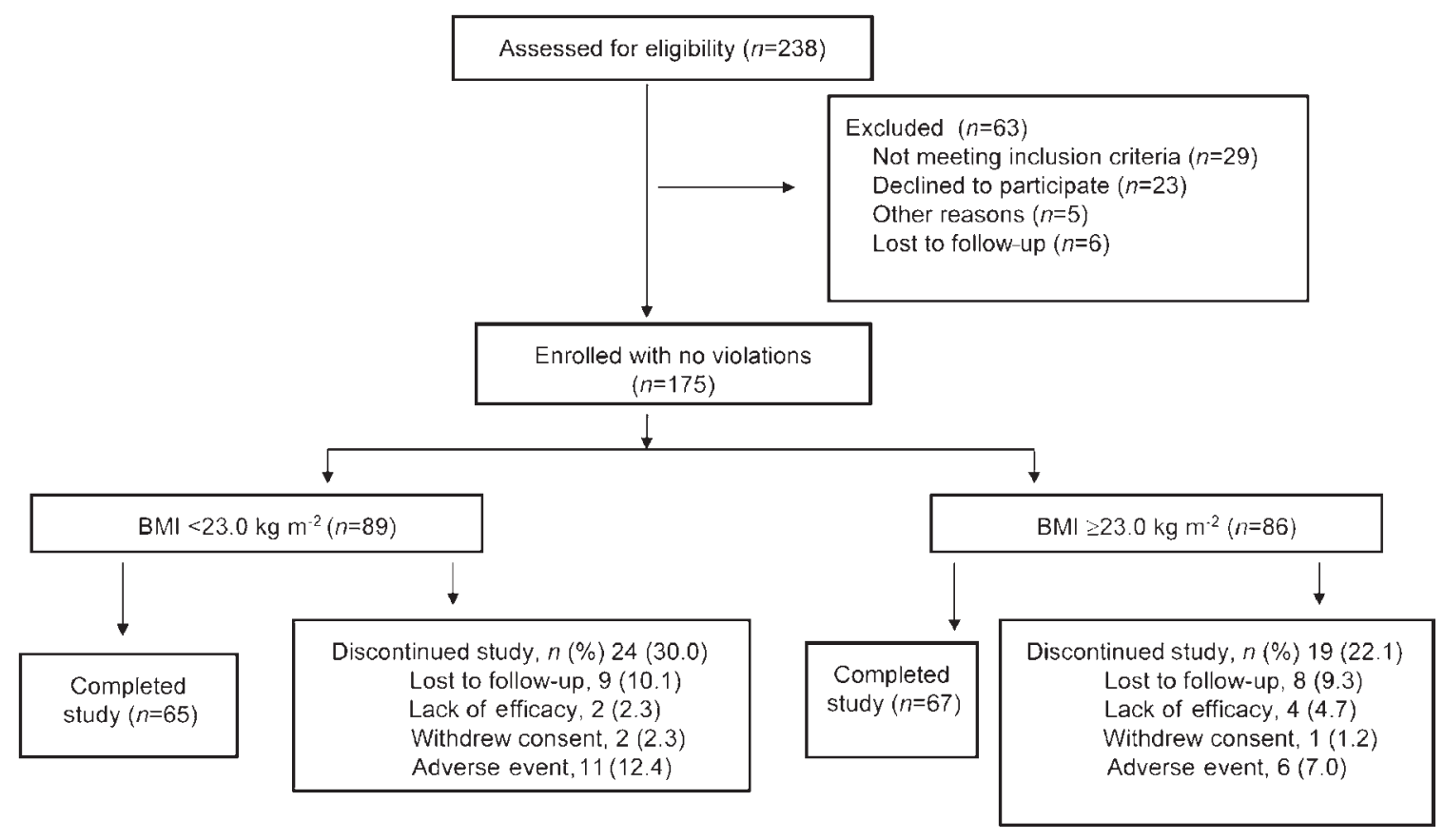

Figure 1 Details of subjects assigned to the study treatment. BMI, body mass index. 
Table 1 Baseline characteristics of study subjects according to waist circumference and BMI

\begin{tabular}{|c|c|c|c|c|}
\hline & Waist circumference $\leqslant 90 \mathrm{~cm}$ & Waist circumference $>90 \mathrm{~cm}$ & $B M I<23.0 \mathrm{~kg} \mathrm{~m}^{-2}$ : normal & $B M I \geqslant 23.0 \mathrm{~kg} \mathrm{~m}^{-2}$ : obese \\
\hline No. & 109 & 66 & 89 & 86 \\
\hline Age (years) & $60.0 \pm 2.9$ & $59.5 \pm 4.0$ & $60.3 \pm 3.1$ & $59.3 \pm 4.8$ \\
\hline Prostate volume (ml) & $32.7 \pm 11.4$ & $36.3 \pm 9.2^{\mathrm{a}}$ & $32.3 \pm 10.1$ & $35.6 \pm 9.7^{d}$ \\
\hline Total IPSS & $19.1 \pm 6.9$ & $22.4 \pm 5.3^{b}$ & $20.5 \pm 7.6$ & $20.9 \pm 7.2$ \\
\hline Voiding symptom subscore & $12.6 \pm 1.0$ & $13.9 \pm 1.4$ & $12.5 \pm 1.1$ & $13.3 \pm 1.0$ \\
\hline Storage symptom subscores & $7.5 \pm 0.8$ & $8.4 \pm 0.7$ & $8.0 \pm 0.4$ & $7.5 \pm 0.6$ \\
\hline Residual volume (ml) & $33.5 \pm 11.7$ & $51.5 \pm 19.1^{c}$ & $32.9 \pm 12.1$ & $37.8 \pm 10.9$ \\
\hline
\end{tabular}

Abbreviations: BMI, body mass index; IPSS, International Prostate Symptom Score; PSA, prostate-specific antigen; $Q_{\max }$, maximal urinary flow rate; QoL, quality of life. The values for prostate volume, PSA, IPSS, QoL and $Q_{\max }$ are expressed as mean \pm s.e.m.

By Student's $t$-test.

${ }^{\text {a }} P=0.026,{ }^{\mathrm{b}} P=0.044,{ }^{\mathrm{c}} P=0.033$, compared with $W \mathrm{C} \leqslant 90 \mathrm{~cm}$;

${ }^{\mathrm{d}} P=0.039$, compared with $\mathrm{BMI}<23.0 \mathrm{~kg} \mathrm{~m}^{-2}$.

The baseline data of the initially enrolled 175 patients are balanced with that of the 132 patients who finished the study.

weeks). All groups showed significant improvements in total IPSS and QoL scores at 12 weeks. The mean changes in total IPSS from baseline to 12 weeks were $-9.3(44.5 \%)$ and $-8.1(39.5 \%)$ points for the high-BMI $(P=0.022)$ and low-BMI groups $(P=0.039)$, respectively, and $-9.8(43.8 \%)$ and $-7.4(38.7 \%)$ points for the high-WC $(P=0.027)$ and low-WC groups $(P=0.031)$, respectively. Compared with the non-obese men, the high-BMI and high-WC groups showed greater reductions in total IPSS at week $12(P=0.034$ and $P=0.021$, respectively). Improvement of the QoL score was not different among groups; all groups showed improvements in QoL at 12 weeks. In the linear regression analysis, the change in the total IPSS between baseline and week 12 following alpha-blocker medication was positively correlated with baseline WC $(P=0.028)$.

$\mathrm{Q}_{\max }$ significantly improved at week $12\left(+2.3 \mathrm{ml} \mathrm{s}^{-1}\right)$ only in the high-WC group. The high-BMI group had a greater reduction in PVR $(-23.1 \mathrm{ml})$ from baseline compared to the other groups at week 12. In all, 17 treatment-related AEs were reported (12.9\%). The most frequent $\mathrm{AE}$ was dizziness, reported by 13 patients (9.8\%). Other AEs were postural hypotension (two, $1.5 \%$ ), gastrointestinal disorder (one patient with gastritis, $0.7 \%$ ) and prostatic disorder (one patient with aggravation of chronic perineal discomfort, $0.7 \%$ ). Dizziness was significantly higher in the low-BMI group $(n=9,10.1 \%)$ compared with the high-BMI group $(n=4,4.7 \%, P=0.042)$.

\section{DISCUSSION}

Our data demonstrate that the total IPSS was positively correlated with central obesity, as represented by waist circumference and prostate volume. Lee et al. ${ }^{12}$ found that centrally obese men had lower testosterone concentrations and greater prostate volumes. Obesity raises

Table 2 Linear regression analyses evaluating factors correlated with total IPSS

\begin{tabular}{lcc}
\hline & Coefficient & P value \\
\hline BMI $\left(\mathrm{kg} \mathrm{m}^{-2}\right)$ & 0.230 & 0.133 \\
Waist circumference $(\mathrm{cm})$ & 0.295 & 0.045 \\
Prostate volume $(\mathrm{ml})$ & 0.327 & 0.031 \\
$Q_{\max }\left(\mathrm{ml} \mathrm{s}^{-1}\right)$ & 0.194 & 0.209 \\
Residual volume $(\mathrm{ml})$ & 0.206 & 0.195 \\
PSA (ng ml & & 0.492 \\
\hline
\end{tabular}

Abbreviations: BMI, body mass index; IPSS, International Prostate Symptom Score; PSA, prostate-specific antigen; $Q_{\max }$, maximal urinary flow rate.

Component is continuous variable. oestrogen levels and free and total estradiol concentrations, while lowering free and total testosterone and serum globulin-binding protein levels. ${ }^{13}$ Greater oestrogen levels in the environment of age- and obesity-induced lower testosterone levels may affect prostate cell growth. However, the extent to which obesity may influence BPH according to sex steroid hormones should be further investigated.

McVary et al. ${ }^{14}$ demonstrated that increased sympathetic tone (autonomic hyperactivity) can result in LUTS and subjective voiding complaints. In particular, abdominal obesity increases the oestrogento-androgen ratio and may increase sympathetic nervous activity, both of which are known to influence the development of BPH and the severity of LUTS. ${ }^{15}$ Among the indices of overweight and body adipose tissue distribution, it is visceral adiposity that is most closely related with
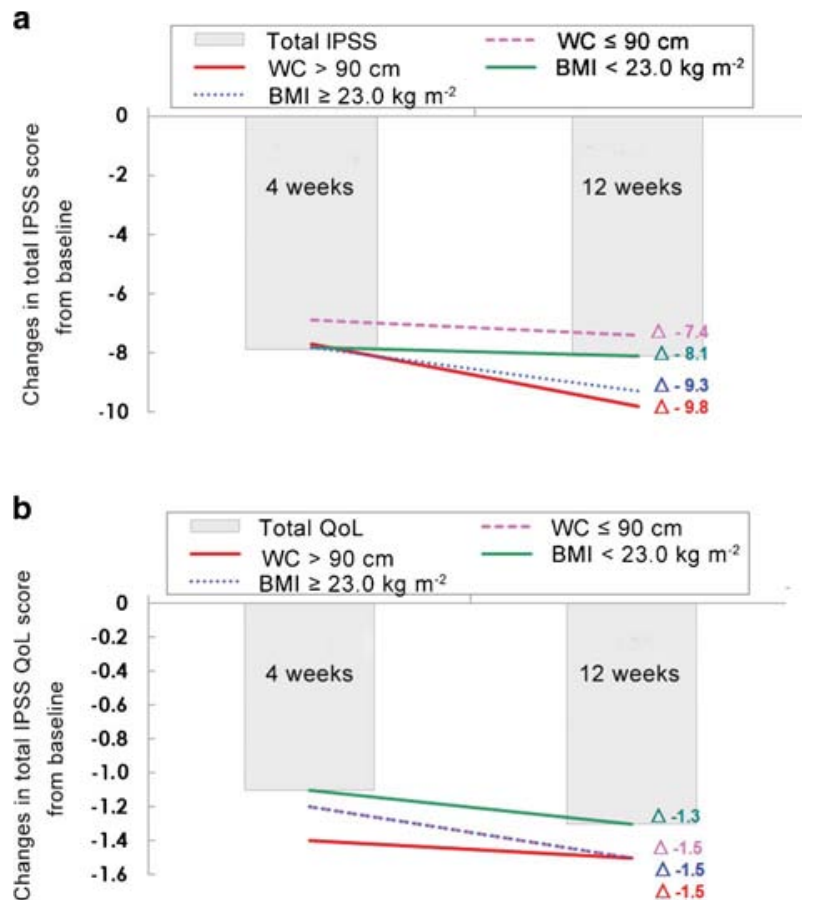

Figure 2 Percentage improvement in total IPSS (a) and QoL scores (b) from baseline ( 0 week) by visit ( 4 and 12 weeks) according to BMI and WC. BMI, body mass index; IPSS, International Prostate Symptom Score; QoL, quality of life; WC, waist circumference. 
sympathetic overactivity. Among the obese patients, the whole body norepinephrine spillover rate is quantitatively linked to waist circumference. ${ }^{16}$ Sympathetic nerve firing rates measured by microneurography have been reported to be $55 \%$ higher in men with elevated abdominal visceral fat levels than in men with only subcutaneous obesity. This increased sympathetic activity in centrally obese men is involved in LUTS/BPH, with norepinephrine and alphal-adrenoceptors representing a common link. ${ }^{17,18}$

Interestingly, we observed significantly greater improvement in the mean change in total IPSS from baseline to week 12 in the high-BMI and -WC groups, even though the low BMI or low WC groups also showed significant improvements at week 12. Furthermore, the centrally obese BPH/LUTS patients showed significant improvement in $\mathrm{Q}_{\max }$ following alpha-blocker medication at week 12 . Obesity is characterized by enlarged depots of adipose tissue, which are metabolically active and secrete numerous hormones and proteins that influence local adipocyte biology as well as distant organ systems. ${ }^{19,20}$ Leptin and tumor-necrosis factor-alpha are hormones secreted from adipose tissue that affect the ingestion of food and body weight. ${ }^{21}$ It is also known that leptin stimulates the cellular proliferation of $\mathrm{BPH}^{22}$ Ueshiba and Miyachi ${ }^{23}$ reported that treatment with the doxazosin improved dyslipidemia in obesity patients. Furthermore, circulating tumor-necrosis factor-alpha and leptin levels decreased significantly within 3 months of doxazosin treatment. ${ }^{23}$ Therefore, doxazosin GITS might have a beneficial effect on adipose endocrine activity in obese patients with $\mathrm{BPH}$.

We previously reported that individuals with more severe IPSS and larger prostate volumes have a higher risk of medical treatment failure, a result that is partially in conflict with the current results. ${ }^{24}$ However, in that report we did not include the anthropometric parameters of $\mathrm{BPH}$ patients, and we included $\mathrm{BPH}$ patients taking 5-alpha-reductase inhibitors. Our results suggest that the effectiveness of alpha-blocker therapy is more complicated and that other factors should be further evaluated in addition to the parameters related to BPH or the clinical pharmacokinetics of doxazosin GITS. In addition, in our study we could not identify significant prognostic factors of non-response to doxazosin GITS due to the limited number of medical treatment failures. Therefore, further study based on a large sample size is needed to elucidate these factors.

This trial should be interpreted within the context of its limitations. It has a relatively short follow-up period and a small sample size despite being a prospective study. However, considering the increasing prevalence of concomitant comorbidities (e.g., hypertension and diabetes mellitus), the size of our sample of patients without any relevant medical history or underlying comorbidities might be adequate to determine statistical significance.

In our study, obesity was associated with increased prostate volume and lower urinary tract symptoms in BPH patients. Doxazosin GITS appears to be safe and efficacious for controlling symptoms, especially in obese men with $\mathrm{BPH}$.

\section{AUTHOR CONTRIBUTIONS}

CYO, SJY and BHC designed the study, MSC, KKP and SHL reviewed the topic, and SHL formed the data analyses described in the manuscript and wrote sections. SHL and MSC revised and edited the article.

\section{COMPETING FINANCIAL INTERESTS}

$\mathrm{BHC}$ has received research support from Pfizer Korea, Ltd.

\section{ACKNOWLEDGMENTS}

This study was supported by grants from Pfizer Korea, Ltd.

1 Saigal CS, Joyce G. Economic costs of benign prostatic hyperplasia in the private sector. J Urol 2005; 173: 1309-13.

2 Parsons JK, Sarma AV, McVary K, Wei JT. Obesity and benign prostatic hyperplasia: clinical connections, emerging etiological paradigms and future directions. J Urol 2009; 182: S27-31.

3 Kim DM, Ahn CW, Nam SY. Prevalence of obesity in Korea. Obes Rev 2005; 6: 117-21.

4 Park YH, Chung MK. The prevalence of clinical benign prostatic hyperplasia and lower urinary tract symptoms in South-East Korea: a community-based study. J Pusan Nat/ Univ Hosp 2001; 9: 141-57.

5 Lee MW, Lee KS. The prevalence of benign prostatic hyperplasia in self-referral populations over aged 50. Korean J Urol 1996; 37: 263-7.

6 Seim A, Hoyo C, Ostbye T, Vatten L. The prevalence and correlates of urinary tract symptoms in Norwegian men: the HUNT study. BJU Int 2005; 96: 88-92.

7 Rohrmann S, Smit E, Giovannucci E, Platz EA. Associations of obesity with lower urinary tract symptoms and noncancer prostate surgery in the Third National Health and Nutrition Examination Survey. Am J Epidemiol 2004; 159: 390-7.

8 Parsons JK, Carter HB, Partin AW, Windham BG, Metter EJ et al. Metabolic factors associated with benign prostatic hyperplasia. J Clin Endocrinol Metab 2006; 91 2562-8.

9 Chung BH, Hong SJ, Lee MS. Doxazosin for benign prostatic hyperplasia: an openlabel, baseline-controlled study in Korean general practice. Int J Urol2005; 12: 15965

10 Chung $\mathrm{BH}$, Hong SJ. Long-term follow-up study to evaluate the efficacy and safety of the doxazosin gastrointestinal therapeutic system in patients with benign prostatic hyperplasia with or without concomitant hypertension. BJU Int 2006; 97: 90-5.

11 World Health Organization. Western Pacific Region. International Association for the Study of Obesity. The Asia-Pacific Perspective: Redefining Obesity and its Treatment. Sydney, NSW: Health Communications Australia Pty Limited; 2000.

12 Lee S, Min HG, Choi SH, Kim YJ, Oh SW et al. Central obesity as a risk factor for prostatic hyperplasia. Obesity 2006; 14: 172-9.

13 Pasquali R, Casimirri F, Cantobelli S, Melchionda N, Morselli Labate AM et al. Effect of obesity and body fat distribution on sex hormones and insulin in men. Metabolism 1991: 40: 101-4.

14 McVary KT, Rademaker A, Lloyd GL, Gann P. Autonomic nervous system overactivity in men with lower urinary tract symptoms secondary to benign prostatic hyperplasia. J Urol 2005; 174: 1327-433.

15 Barqawi AB, Golden BK, O'Donnell C, Brawer MK, Crawford ED. Observed effect of age and body mass index on total and complexed PSA: analysis from a national screening program. Urology 2005; 65: 708-12.

16 Poehlman ET, Gardner AW, Goran MI, Arciero PJ, Toth MJ et al. Sympathetic nervous system activity, body fatness and body fat distribution in younger and older males. J Appl Physiol 1995; 78: 802-6.

17 Alvarez GE, Beske SD, Ballard TP, Davy KP. Sympathetic neural activation in visceral obesity. Circulation 2002; 106: 2533-6.

18 Eckel RH, Grundy SM, Zimmet PZ. The metabolic syndrome. Lancet 2005; 365: 1415-28.

19 Haque WA, Garg A. Adipocyte biology and adipocytokines. Clin Lab Med 2004; 24 217-34.

20 Considine RV, Sinha MK, Heiman ML, Kriauciunas A, Stephens TW et al. Serum immunoreactive-leptin concentrations in normal weight and obese humans. N Engl J Med 1996; 334: 292-5.

21 Malendowicz W, Rucinski M, Macchi C, Spinazzi R, Ziolkowska A et al. Leptin and lepin receptors in the prostate and seminal vesicles of the adult rat. Int $\mathrm{J} \mathrm{Mol} \mathrm{Med}$ 2006; 18: 615-8.

$22 \mathrm{Kim}$ JH, Lee SY, Myung SC, Kim YS, Kim TH et al. Clinical significance of the leptin and leptin receptor expressions in prostate tissues. Asian J Androl 2008; 10: 923-8.

23 Ueshiba $\mathrm{H}$, Miyachi $\mathrm{Y}$. Effect of doxazosin on insulin resistance in hypertensive patients with obesity. Horm Metab Res 2003; 35: 532-6.

24 Hong SJ, Ko WJ, Kim SI, Chung BH. Identification of baseline clinical factors which predict medical treatment failure of benign prostatic hyperplasia: an observational cohort study. Eur Urol 2003; 44: 94-9. 